\title{
The Social Capital Relation Network Analysis of Chinese Governors
}

\author{
Guanqiong Yang, An Huang \\ Beijing Normal University, Beijing, China \\ Email: ha163yx@163.com
}

How to cite this paper: Yang, G. Q., \& Huang, A. (2017). The Social Capital Relation Network Analysis of Chinese Governors. Open Journal of Political Science, 7, 326-334.

https://doi.org/10.4236/ojps.2017.72026

Received: March 15, 2017

Accepted: April 25, 2017

Published: April 28, 2017

Copyright $\odot 2017$ by authors and Scientific Research Publishing Inc. This work is licensed under the Creative Commons Attribution International License (CC BY 4.0).

http://creativecommons.org/licenses/by/4.0/

\begin{abstract}
The social relation network of officials has an important effect on official promotion. Nowadays the measurement of the network is focused on the individual network of officials, and the research about measuring the whole network between officials is scarce. This article collects the samples from 154 Governors since 2000, defines and measures the Governors network from the view of the whole network through Ucinet, a Social Network Analysis software. Based on the identification of network border, the article defines the Governors network as the direct and indirect relation set of Governors having worked in the same province, and analyzes the density and centrality of the network. What's more, it carries on the expanded research, trying to explore the relationship between Governors network and official promotion. It will increase the measurement index of social network and provide reference for more quantitative research on the relation between social network and official promotion.
\end{abstract}

\section{Keywords}

Governors Network, Density, Centrality, Official Promotion

\section{Introduction}

The researches about Official Governance focus on Official Promotion, Official Behavior and Accountability Supervision (Zhu \& Mao, 2017). During those themes, the promotion most appeals to the scholars, which mainly analyzes the factors having effects on Official Promotion. The factors contain officials' personality, the economic performance in office, political background and social relation. There are many indexes based on the individual relation network to measure the officials' social relation. For example, Opper and Brehm (2007) construct a Network Ties Index to reflect the strength of relation network, which roundly judges three kinds of relationship between Leaders and Members of the 
Standing Committee of the Political Bureau: the fellow, alumnus, and colleagues. However, this kind of research actually ignores the interaction relationship between officials including the direct relation and indirect relation. And thus, it forms the social network of Leaders (Xie \& Chen, 2012). Granovetter (1973) put forward a hypothesis of the strength of weak ties, and it means that the opportunity having different information is gained through the weak ties, connecting itself to the local network in some distance. And the weak ties will construct the instrumental relation and contribute to the achievement of instrumental goals. The article clearly defines the Governors Network, analyzes the density and centrality of the network and tries to discuss the relation between the network and officials promotion time. It can enrich the indicators of relation network and help other scholars further understand the official behavior.

\section{The Definition of Governors Network}

\subsection{The Boundedness of the Researches}

The measurement for Governors Network mainly discusses the effect which relation network behind Governors has on career development. And it is based on individual network from the view of social network analysis. The NTI by Opper and Brehm (2007) and Strength of Indirect Relation by Bian are aimed to measure varied relation or political background of their parents behind every official. However, they didn't build the interaction relation between officials. This kind of relation is a common link based on the same working district during their promotion career.

\subsection{The Definition of Governors Network}

Provincial leaders, the important governor, play diverse social roles and are affected by different kinds of person. Governors Network belongs to a special social network, so we should clarify the concept of social network. Social network refers to the collection of social actors and their relationships (Liu, 2004) and is a combination of nodes and their relationship (lines). A node can either represent a person or an organization, both as an actor. The links between Individuals and individuals, individuals and organizations, organizations and organizations are known as the relationship. To this end, this paper defines the shadhoders network as follows:

The collection of direct and indirect ties based on the same administrative area in the promotion process.

In the shadholders network, a node is an individual governor in the whole network, and the link is constructed based on the same administrative district. For example, governor A worked in Hubei Province for two years in the promotion process and worked in Hunan Province for five years, while Governor B worked in Hunan Province for three years and worked in Jiangxi Province for five years. Then Governor A and B are connected. The information and resources of the same administrative region in the short term are stable, and the governor will produce the similar governance behavior by using common re- 
sources and geographical location. And this is an indirect link. There is also a special case that the two governors in the same area worked as a different position, which will form a direct relation. In both cases, the network relationship is informal and loose. After the important role of informal relations from the Hawthorne Experiment, Linnan proposed that the social network is a weak fomal social structure from the perspective of social capital theory (Lin, 2002).

\subsection{The Boundness of Governors Network}

The network is a collection of points with boundaries, so the Governors network must be defined before the study. The relationship network between the governors contains many types, such as fellow relations, friends relations, alumni relations, and colleagues' relationships, but we only consider the governor relations based on working in at least one area for the following reasons: we cannot measure the comprehensive Governors network, because an individual in the political and economical society plays a variety of roles and forms a different network of relationships. More is a private relationship, for example, in the $\mathrm{Na}$ tional People's Congress they become friends. This relationship cannot be defined. And it's hard to have an empirical analysis and get complete correlation data. Even if the Internet has a lot of information, it is still ambiguous and one-sided. Compared with the private relations, it is easier to measure the Shadholderes Network based on the same area in the promotion process.

\section{Research Data and Analysis Software}

\subsection{Research Data}

Social network analysis measures relation data, including matrix data between actors and actors and long matrix data (such as affiliation data) between actors and events. This paper uses the form of affiliation relation matrix to collate the relation data and produces a table including the working years in every region. Through the Minimum Method, this article turns the original data (2-mode network data using of) into two kinds of 1-mode data: COLUMN matrix Data (column mode) and ROW matrix data (line mode). The column pattern data is the "Serving area - Serving area" relationship data, reflecting the relationship between 31 mainland provinces, while line mode data is "Governor - Governor "relationship data, reflecting the power relation and interaction between the governors. And this article is mainly concerned with the line mode data.

Considering the availability of effective data and the significance of governors playing the roles in regional governance, this paper takes sample of 154 governors serving 34 mainland provinces since 2000, and obtains data from the analysis of their resumes. The way of gathering the resumes is mainly from China Leading Cadres Database ${ }^{1}$, supplemented publicity information by the People's Network $^{2}$ and Xinhua News Agency ${ }^{3}$. In order to protect the privacy of individ-

${ }^{1}$ The website: http://cpc.people.com.cn/gbzl/index.html

${ }^{2}$ The website: http://renshi.people.com.cn/

${ }^{3}$ The website: http://www.xinhuanet.com/politics/rs.htm 
uals, this study will encode the provincial executive heads, such as the Mayor of Beijing in 2000 as 1.1, Beijing Mayor in 2001 as 1.2, and so on.

\subsection{Analysis Software}

Social Network Analysis is the main tool in the field of sociology, commonly used software including UCINET, Pajek and Netdraw. For processing small sample matrix data, the simplest and most common software is UCINET, developed by Borgatti, Everett and Freeman, handling the raw data in matrix format. This article uses the English version of UCINET6.560 and it not only can draw the network density, centrality, structure hole and other social network indicators, but also is embedded with Netdraw visual analysis, easy to see more intuitive results.

\section{Governors Network}

\subsection{Network Density Analysis}

Network density is the most commonly used measurement of social network analysis. Its calculation is related to the number of lines in the network, reflecting the degree of tightness and interaction between nodes in the network graph (Stanley \& Catherine, 2012). The greater the density of the network is, the closer and more frequent the link is; otherwise, then less interaction, loose contact. We often combine the network density analysis with the network distance and diameter. And the distance refers to the "the shortest path length between the two nodes" (Liu, 2004), while the diameter means the "The longest ground length" (Liu, 2004). On the basis of distance, we can also generate cohesion index. The larger the index is, the more cohesive the network is, that is, the relationship between the network nodes is close and the cohesion is strong.

According to the 1-mode matrix data, along the Network-Visualize-Netdraw we can draw the governors interactive network as Figure 1. The overall density of the network is 0.2 , indicating that the interaction between the governors is not frequent enough and the relationship is not close enough. The average distance of the network is about 2, indicating that the governors' communication is convenient and each governor can establish contact with any other governor on average only through the two governors. The diameter of the network is 5, indicating that any two governors can interact and contact with up to five governors. The cohesion index of the network is 0.720 , indicating that the social solidarity of the network based on the interaction between the governors is relatively high.

\subsection{Centrality Analysis}

In the social network analysis, the centrality is used to quantify the power. Centrality is used to understand the power and influence of actors in the network and indicates the central degree of the whole network. In the network, nodes in the central location are more likely to acquire resources and information, have greater power and greater influence on other nodes (Weng \& Zhang, 2016). Scholars have proposed the different forms of the centrality: the centrality 


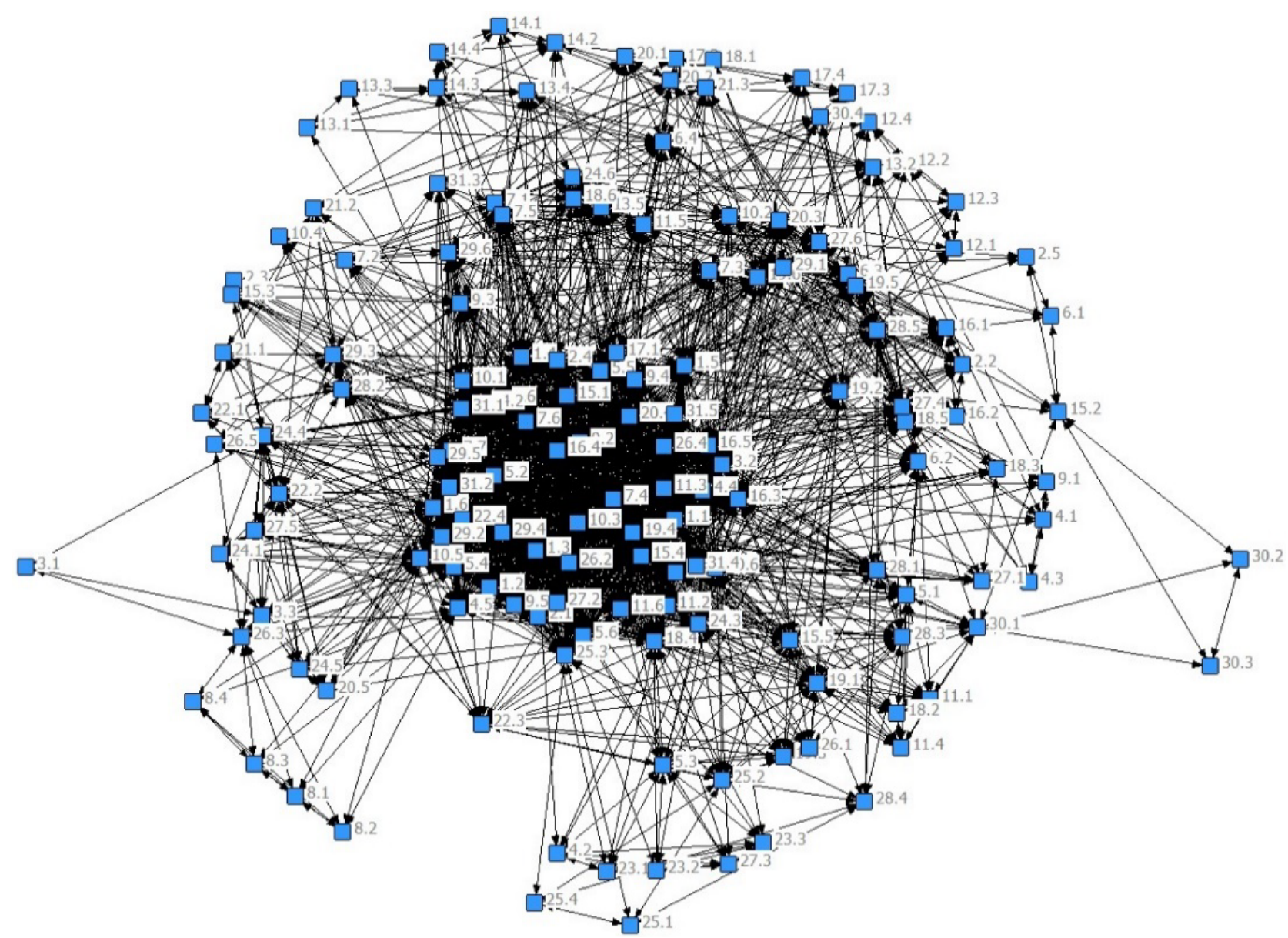

Figure 1. The Governors interaction network based on the same administrative area.

degree is used to describe the core of the nodes in the network; the between centrality is the degree of actors' control to the resources, which measures the ability to control other actors (Freeman, 1979); closeness centrality degree measures the ability not to be controlled by other actors ; eigenvector centrality is used to find core members in the network.

The four network centrality metrics for each governor can be calculated along the path of Network-Centrality and Power-Multiple Measures (see Table 1). In the centrality indexes, the degree, the between centrality and the eigenvector centrality are the high excellent indexes, that is, the larger the value is, the higher the centrality degree is, but the closeness centrality based on the distance is the low excellent index, that is, the smaller the value is, the higher the centrality degree is. From the data, we can be see that the highest degree of the degree centrality and between centrality and the lowest of closeness centrality are the former mayor in Beijing, respectively 78, 860.293, 230, indicating that this node is not only occupied in the core position in the entire provincial network, but also has the ability to strongly control resources and to be least affected by other governors. And the highest degree of eigenvector centrality is 0.141 , higher than the former mayor of Beijing 0.001, indicating that this node, the former governor in Shanxi Province is the core member of Shadholders Network. 
Table 1. Centrality measures (part).

\begin{tabular}{ccccc}
\hline Code & Degree & Between & Closeness & Eigenvec \\
\hline 1.1 & 56 & 56.563 & 254 & 0.131 \\
1.2 & 52 & 0 & 258 & 0.13 \\
1.3 & 68 & 329.287 & 241 & 0.138 \\
1.4 & 72 & 448.631 & 238 & 0.138 \\
1.5 & 78 & 860.293 & 230 & 0.14 \\
1.6 & 63 & 120.598 & 246 & 0.135 \\
2.1 & 52 & 0 & 258 & 0.13 \\
2.2 & 18 & 0 & 322 & 0.02 \\
2.3 & 11 & 0 & 362 & 0.018 \\
2.4 & 58 & 182.98 & 252 & 0.131 \\
2.5 & 6 & 0 & 361 & 0.004 \\
2.6 & 64 & 84.761 & 245 & $\ldots .138$ \\
$\ldots$ & $\ldots$ & $\ldots$ & 242 & $\ldots .138$ \\
31.5 & 68 & 147.732 & & $\ldots$ \\
\hline
\end{tabular}

But it has litter significance to independently analyze the highest value of each indicator, so a comprehensive network indicator is needed. Wasserman and Faust (1994) argue that the centrality degree, the between degree, the closeness centrality, and the eigenvector centrality are a part of centrality concept. Each indicator has its advantages and utility, and should not use any centrality index by itself. In order to more comprehensively measure the provincial interaction network, this article will consider this indicator. The specific data process is as follows: (1) In order to eliminate the difference in the dimension of each centrality index, the above four network centrality values are sorted and divided into ten groups, assigned 0 - 9 as the network centrality ranking index; (2) Calculate the average value of the four sorting indicators as the comprehensive provincial centrality value. From the calculation results, we can see that the centrality value of 9 have four nodes, three of which are the former mayor in Beijing and the other is from Jilin Province, indicating that they are in the core position in Shadholders Network and have some influence on the behavior of other governors.

\section{Explend Researches and Boundness}

\subsection{Shadholders Network and Leaders Promotion}

In the researches of officials promotion, the Promotion Tournament has been the mainstream, but many scholars through the empirical test found that the relation network, have a more important impact on the officials promotion. But the measurement of the relationship is very difficult, and the most representative 
is the NTI index and indirect relationship strength. However, this paper discovers that the Shadholders Network reflecting the interaction relationship can also be used as a measurement. The following is a brief discussion of the possible relationship between centrality and the promotion period of the officials.

According to the basic description of the 154 governors, it takes nearly 34 years for governors from the beginning of the work to the shadholders. The average age when being leader of the province is 56 years old. Table 2 shows the promotion time of the executive head of the integrated centrality index above 8.5. As can be seen from the table below, the average promotion time for 17 chief executives is 32 years, below the average of all data. Thus, the author can speculate that the central shadholders may need a shorter promotion time.

\subsection{Shadholders Network and the Quantity of Serving Areas}

Among the four governors with the highest comprehensive centrality values, there is one thing in common: they have worked in four or more different regions, where the largest number of serving areas is the former mayor from Beijing, working in six regions including Beijing, Shanghai, Henan, Gansu, Jilin and Xinjiang, followed by Governor Jiang from Jilin Province, who has been promoted in the five regions of Beijing, Shandong, Hubei, Hunan and Guangdong. Table 3 shows the centrality index of four or more governors. As can be seen

Table 2 . The promotion time of centrality values $\geq 8.5$.

\begin{tabular}{|c|c|c|}
\hline Code & Centrality & Promotion Time \\
\hline 7.7 & 8.5 & 22 \\
\hline 18.4 & 8.5 & 28 \\
\hline 24.2 & 8.5 & 29 \\
\hline 26.4 & 8.5 & 32 \\
\hline 31.1 & 8.5 & 26 \\
\hline 31.5 & 8.5 & 35 \\
\hline 3.2 & 8.75 & 33 \\
\hline 7.4 & 8.75 & 32 \\
\hline 9.4 & 8.75 & 34 \\
\hline 10.5 & 8.75 & 34 \\
\hline 11.3 & 8.75 & 36 \\
\hline 16.3 & 8.75 & 40 \\
\hline 31.2 & 8.75 & 27 \\
\hline 1.3 & 9 & 32 \\
\hline 1.4 & 9 & 38 \\
\hline 1.5 & 9 & 32 \\
\hline 10.6 & 9 & 37 \\
\hline AVERAGE & & 32 \\
\hline
\end{tabular}


from the table, only the centrality index of node 27.6 is lower, and the centrality index of other nodes is above 8.75.

In order to explore the reasons for the existence of singularity 27.6 in the above table, the author lists the hot areas where the governor has served in the promotion process, that is, at least 10 governors served as the area (hereinafter referred to as the popular area, see Table 4). From the resumes of the nine governors of Table 3, the other eight governors have served at least one popular area, except for the governor 27.6, which is the reason for his low centrality value. Thus, the author can speculate that under the premise of serving in the popular areas, there is positive relationship between the quantity of serving areas and centrality.

These are expansion analysis and speculation, which does not undergo a rigorous regression analysis and nonparametric test, which is the shortcomings of this article.

Table 3 . The centrality of quantity of serving areas $\geq 4$.

\begin{tabular}{ccc}
\hline Code & Quantity of Serving Areas & Centrality \\
\hline 1.3 & 4 & 9 \\
1.4 & 4 & 9 \\
9.4 & 4 & 8.75 \\
10.5 & 4 & 8.75 \\
11.3 & 4 & 8.75 \\
27.6 & 4 & 5.75 \\
31.2 & 4 & 8.75 \\
10.6 & 5 & 9 \\
1.5 & 6 & 9 \\
\hline
\end{tabular}

Table 4. Popular serving areas.

\begin{tabular}{cc}
\hline Region & The quantity of serving governors \\
\hline Beijing & 52 \\
Jiangsu & 18 \\
Shanxi & 17 \\
Zhejiang & 14 \\
Heilongjiang & 14 \\
Liaoning & 13 \\
Hunan & 13 \\
Jiangxi & 11 \\
Hebei & 11 \\
Gansu & 10 \\
Sichuan & 10 \\
\hline
\end{tabular}




\section{Conclusion}

Through the analysis of the governors' interaction network, this paper found that the communication between the governors is more convenient, and through the two governors a link can be established with any other governors; from the core power of the governors' promotion time, certain relation between centrality and promotion speed can be predicted. In addition, in the statistical analysis of the 154 governor's resumes, it was found that Beijing, Jiangsu and Shanxi became popular areas during the promotion of the governor, and officials needed an average of 34 years to promote to the governor level. The author hopes that through the description and analysis of the Governors network, it is helpful for the future study of the relationship between the Governors network and the officials promotion.

\section{References}

Freeman, L. (1979). Centrality in Social Networks: Conceptual Clarification. Social Networks, 1, 215-239.

Granovetter, M. (1973). The Strength of Weak Ties. American Journal of Sociology, 78, 1360-1380.

Lin, N. (2002). Social Capital: A Theory of Social Structure and Action. Cambridge: Cambridge University Press.

Liu, J. (2004). The Introduction of Social Network Analysis (p. 12). Beijing: Sociology Literature Press.

Opper, S., \& Stefan, B. (2007). Networks versus Performance: Political, Leadership Promotion in China.

Stanley, W., \& Catherine, F. (2012). Social Network Analysis: Method and Application. Beijing: China Renmin University Press.

Weng, S., \& Zhang, Y. (2016). Social Network Analysis of Micro-Blog Public Opinion Interaction in Public Agenda Setting. Journal of Wuhan University (Humanities and Social Sciences), No. 1, 109-118.

Xie, D., \& Chen, Y. (2012). Director Network: Definition, Characteristics and Measurement. Accounting Research, No. 3.

Zhu, C., \& Mao, W. (2017). Study and Prospect of Official Governance Research: Bibliometrics and Content Analysis Based on CSSCI. Local Governance Research, No. 1. 
Submit or recommend next manuscript to SCIRP and we will provide best service for you:

Accepting pre-submission inquiries through Email, Facebook, LinkedIn, Twitter, etc. A wide selection of journals (inclusive of 9 subjects, more than 200 journals)

Providing 24-hour high-quality service

User-friendly online submission system

Fair and swift peer-review system

Efficient typesetting and proofreading procedure

Display of the result of downloads and visits, as well as the number of cited articles Maximum dissemination of your research work

Submit your manuscript at: http://papersubmission.scirp.org/

Or contact ojps@scirp.org 